Care should be taken, however, to dry the apparatus thoroughly after sterilization. This is easily accomplished in the autoclave, by the use of either a vacuum drying arrangement or the application of dry heat.

2. The chuck $(B)$ at the end of the shaft fits any bit, having a diameter of its shaft up to $1 / 4$ inch. This does away with the necessity of obtaining specially designed drills for the instrument. As a matter of fact, most of the drills and burrs used by ourselves have been selected from a machinist's catalog, and were found to fit and be of service without alteration. As most of these tools are carried in stock by most hardware houses, the cost is quite small.

3. The outer shelt, when removed, exposes the motor completely, allowing repairs to be easily made and permitting constant attention to be exercised over the working of the motor and connections.

4. The control $(A)$, giving three speeds and a stop, is directly under the thumb of the operator and can be worked from any position. The speeds are 1,200, 1,800 and 4,500 revolutions per minute.

5. The pistol grip permanent handle $(D)$ gives the operator a safe and sure grasp of the instrument in his major hand. As it is hollow, the room afforded on the inside gives a convenient place for the storage of the resistance coils.

6. A second grip $(C)$ fits by means of a broad band over the larger part of the shell, and can be changed by a twist of the wrist to assume any position around the circumference, thus not only permitting of adjustment for various positions necessary during operations, but also allowing for use in both right and left handed individuals.

7. The weight of the entire instrument is $53 / 4$ pounds and its length is $111 / 4$ inches. It can be attached to any electric fixture supplied with either direct or alternating current.

The instrument was made by the Southern Electrical Company of San Diego, Calif.

St. Joseph's Hospital.

\section{A NEW BLADDER RETRACTOR}

\section{B. A. Thomas, M.D., Philadelphia}

An ideal retractor in suprapubic cystotomy, particularly for exposure of the vesical trigon, does not exist. The chief difficulty has been to obtain a satisfactory exposure of the fioor of the bladder and the ureteral orifices. Ordinarily two things occur to prevent this: First, when lateral retraction is made by simple vertical-bladed instruments, the floor and fundus of the viscus bulge up and down respectively, obscur-

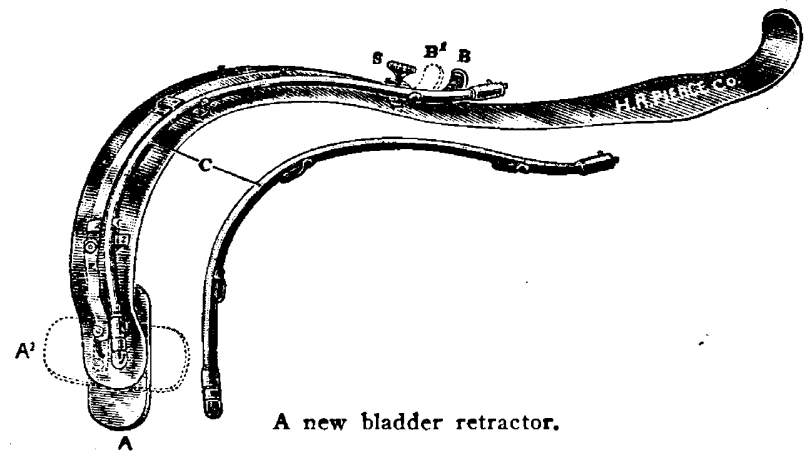

ing the ureteral orifices; second, the illumination of the operative field is either clumsy or insufficient.

The instrument here illustrated and described is essentially a Deaver retractor, or has the curve of this abdominal retractor, with certain important attachments which in my experience have made it most serviceable. The features of this new instrument are:

1. An adjustable cross-blade, $A$, which after introduction into the bladder by slight pressure at $B$, may be swung out as seen in $A^{\prime}$. A set screw, $S$, fixes the blade in the horizontai position.
2. A removable light carrier, $C$, permitting the major part of the instrument to be sterilized by boiling; the lamp-carrier being conveniently sterilized in cold solution of liquor formaldehydi.

3. The lamp is particularly well constructed, sheds an excellent light and is very durable.

4. The instrument is thin, although very firm, therefore occupying very little space in the suprapubic opening and allowing unobstructed vision and opportunity for operative manipulations.

With two such retractors in lateral positions, one only necessarily equipped with the lighting device, and possibly a third simple Deaver retractor to hold up the upper angle of the wound and fundus, an operative field, par excellence, can readily be exposed.

116 South Nineteenth Street.

\section{SUCTION TUBES FOR USE IN THE NOSE, THROAT OR EARS* \\ Harold Hays, M.D., New York \\ Fellow of the American Coilege of Surgecns}

The tubes illustrated are designed for removing small amounts of secretions from the nose, throat or ears. They are made of glass and are fitted to a suction pump. Near

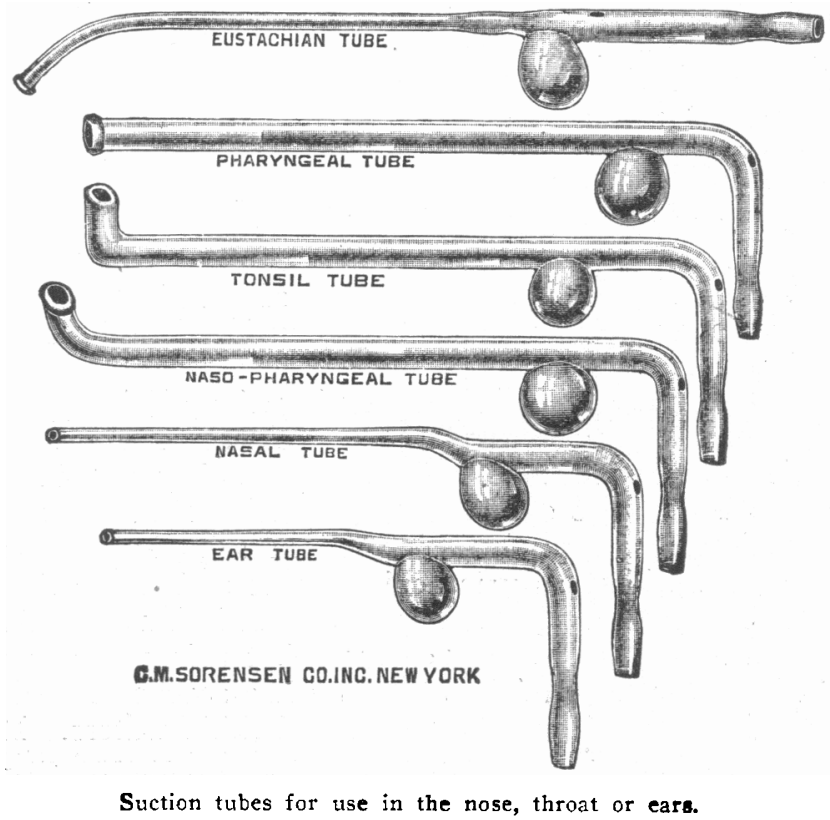

the angle the glass is blown into a bulb into which the secretion will run. Just beyond the angle is a small hole so that even though the pump is turned on no suction is created until this hole is closed by the finger. In order to clean the tubes, water is run through them and then the excess of secretion is cleaned out by attaching the tube to the compressed air apparatus. If this does not succeed, one may start suction and thus draw water through them until they are perfectly clean. These tubes are readily boiled and are more durable than one would suppose.

11 West Eighty-First Street.

* Presented before the Otological Section of the New York Academy of Medicine, May 8, 1915 .

Tuberculosis in Europe.-Tuberculosis statistics show that in Europe about 90 per cent. of all grown persons have been unable to defend themselves from tuberculous infection.- A. Calmette-Lille. 